\title{
A performance evaluation of the ejector refrigeration system based on thermo- economic criteria through multi-objective approach
}

\author{
Mansuriya, Kiran; Patel, Vivek K.; Desai, Nishith B.; Vora, Nilesh M.
}

Published in:

Clean Technologies and Environmental Policy

Link to article, DOI:

10.1007/s10098-020-01884-1

Publication date:

2021

Document Version

Peer reviewed version

Link back to DTU Orbit

Citation (APA):

Mansuriya, K., Patel, V. K., Desai, N. B., \& Vora, N. M. (2021). A performance evaluation of the ejector refrigeration system based on thermo-economic criteria through multi-objective approach. Clean Technologies and Environmental Policy, 23, 1087-1103. https://doi.org/10.1007/s10098-020-01884-1

\section{General rights}

Copyright and moral rights for the publications made accessible in the public portal are retained by the authors and/or other copyright owners and it is a condition of accessing publications that users recognise and abide by the legal requirements associated with these rights.

- Users may download and print one copy of any publication from the public portal for the purpose of private study or research.

- You may not further distribute the material or use it for any profit-making activity or commercial gain

- You may freely distribute the URL identifying the publication in the public portal 


\title{
A performance evaluation of the ejector refrigeration system based on thermo-economic criteria through multi objective approach
}

\author{
Kiran Mansuriya ${ }^{1,4} \cdot$ Vivek K. Patel $^{1,{ }^{*}} \cdot$ Nishith B. Desai ${ }^{2} \cdot$ Nilesh M. Vora ${ }^{3}$
}

1 Department of Mechanical Engineering, Pandit Deendayal Petroleum University, Gandhinagar, Gujarat, India

2 Department of Mechanical Engineering, Technical University of Denmark, Kongens Lyngby, Denmark

3 Application Engineer, Compression Technologies and Services, Ingersoll Rand (India) Limited, Ahmedabad, Gujarat, India

4 Mechanical Engineering Department, Adani Institute of Infrastructure Engineering, Ahmedabad, Gujarat, India

\begin{abstract}
:
This work investigates an exhaust heat-driven ejector refrigeration system with the thermoeconomic considerations. The system is thermally modelled and is optimized considering the performance coefficient and the total annual cost as two objectives using heat transfer search algorithm. Generator temperature, evaporator temperature and condenser temperature are considered as design variables. A 2-dimensional shock circle model is used to simulate the ejector component with R245fa refrigerant. The results of multi-objective optimization are discussed using the Pareto frontier obtained between both conflicting objective functions. The effect of varying the nozzle throat diameter and the ecological function on the thermoseconomic objectives is presented and discussed. The sensitivity analysis of the objective functions to the decision variables is investigated. Further, the exergo-economic results at the
\end{abstract}


optimal point are also presented and discussed. The results reveal that the ejector and the generator are the leading contributors to the exergy destruction and hence to the total annual cost. The coefficient of performance and total annual cost at the best optimal point are 0.3 and $25,903 \$ / y$, respectively. The optimized product unit cost of the system is $53.8 \$ / G J$ with $10.5 \%$ exergy efficiency.

\section{Graphical Abstract:}

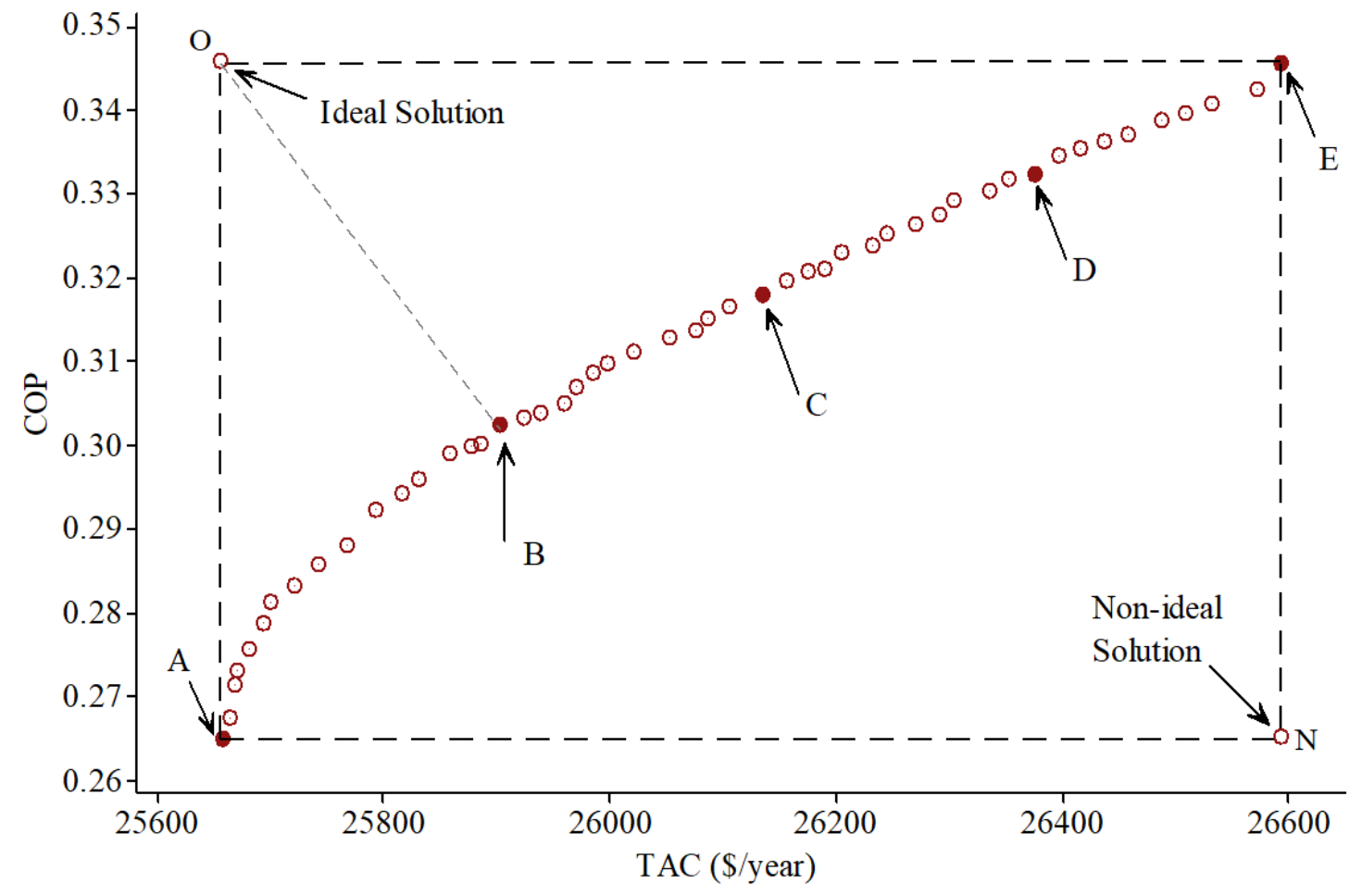

Keywords: Ejector refrigeration; optimization; Thermo-economic analysis; heat transfer search algorithm. 


\section{Nomenclature}

\section{List of symbols}

\begin{tabular}{|c|c|}
\hline$A$ & Area $\left(\mathrm{m}^{2}\right)$ \\
\hline$C_{p}$ & Specific heat $(\mathrm{J} / \mathrm{kg}-\mathrm{K})$ \\
\hline $\mathrm{COP}$ & Coefficient of performance (-) \\
\hline CRF & Capital recovery factor $\left(\mathrm{y}^{-1}\right)$ \\
\hline$\dot{C}$ & Exergy cost rate $(\$ / y)$ \\
\hline$\dot{C}_{Q}$ & Exergy cost rate associated with heat transfer $(\$ / y)$ \\
\hline$\dot{C}_{W}$ & Exergy cost rate associated with work transfer $(\$ / y)$ \\
\hline$D$ & Diameter (m) \\
\hline$\dot{E}$ & Exergy rate $(\mathrm{W})$ \\
\hline$h$ & Specific enthalpy (J/kg-K) \\
\hline$H$ & Pump energy head (m) \\
\hline$M$ & Mach number (-) \\
\hline $\mathrm{MF}$ & Maintenance factor (-) \\
\hline$\dot{m}$ & Mass flow rate $(\mathrm{kg} / \mathrm{s})$ \\
\hline $\mathrm{N}$ & Velocity distribution exponent (-) \\
\hline$P$ & Pressure $(\mathrm{Pa})$ \\
\hline$\dot{Q}$ & Heat transfer rate $(\mathrm{W})$ \\
\hline$R$ & Radius (m) \\
\hline$R_{g a s}$ & Gas constant (J/kg-K) \\
\hline$s$ & Specific entropy $(\mathrm{J} / \mathrm{kg}-\mathrm{K})$ \\
\hline$T$ & Temperature (K) \\
\hline TAC & Total annual cost $(\$ / y)$ \\
\hline$u$ & Unit cost (\$/GJ) \\
\hline
\end{tabular}


$\bar{V}$

$\dot{W}$

Z

$\dot{Z}$

\section{Greek letters}

$\eta$

$\eta_{s, p}$

$\eta_{m, p}$

$\Gamma$

\section{Subscripts}

$\begin{array}{ll}\text { Cr } & \text { Condenser } \\ g & \text { Evaporator } \\ p & \text { Generator } \\ s & \text { Primary flow } \\ d & \text { Secondary flow } \\ \mathrm{D} & \text { Diffuser } \\ \mathrm{F} & \text { Destruction } \\ t & \text { Fuel } \\ e 1 & \text { Nozzle throat } \\ e 2 & \text { Primary nozzle exit } \\ p a & \text { Constant area section } \\ s a & \text { Primary flow at a-a } \\ & \text { Secondary flow at a-a }\end{array}$

Efficiency

Pump isentropic efficiency

Pump mechanical efficiency

Adiabatic index 
$m$

$i$, in

$e, e x$

$\mathrm{O}$

K

Abbreviations

ECF

HTS

IC
Mixed flow

Inlet

Exit

Reference state

Component

Ecological function

Heat transfer search

Internal combustion engine 


\section{Introduction}

In today's era, the increasing need for air conditioning has led to its larger share in electricity consumption worldwide. Due to this, low-grade energy-driven refrigeration systems are drawing more attention to the researchers. Ejector refrigeration system is one of such systems being more reliable as it contains no mobile parts and can have more environment-friendly potential compared to the conventional compression-based refrigeration systems. However, ejector refrigeration systems are unable to penetrate the market due to its low performance coefficient and difficulty in design. Many researchers have investigated the performance of the ejector refrigeration systems and the ejector component especially.

To predict the ejector performance, Huang et al. (1999) used a 1-dimensional model. The authors have assumed the chocked flow condition with constant pressure mixing and uniform velocity distribution in the mixing chamber. The experimental and numerical performances were noted and compared with choked flow condition. With the experimental results, the 1-D model was able to predict the entrainment ratio and the area ratio values within $23 \%$ and $9 \%$ maximum deviation respectively. This $1-\mathrm{D}$ model algorithm was later used with modifications by Chen et al. (2013) and Tashtoush et al. (2015). Chen et al. (2013) suggested a 1-D model for ejector at the critical as well as sub-critical operational mode. The mixing of primary and secondary streams at constant pressure in the constant area zone was assumed and the entrainment ratio values predicted by the model were compared with the experimental values of Huang et al. (1999) and found the maximum deviation of $14.2 \%$. Recently, a simplified ejector model was proposed by Liu et al. (2017) based on the model of Huang et al. (1999). The model has expressed the ejector entrainment ratio and the backpressure by linear expressions. The authors reported the performance prediction comparison with experimental results within $4 \%$ deviation. These 1-dimentional models were assuming the uniform velocity at a particular $y-y$ section and were not considering the 
viscous effect near the ejector walls in the mixing chamber. To consider the viscosity effects at the inner wall of the mixing chamber of the ejector, Zhu et al. (2007) proposed a 2dimensional shock-circle model considering the exponential velocity distribution at any $y-y$ section. It was assumed that the mixed flow of primary and secondary streams gets chocked (Mach number $=1)$ at the thin intersection layer between these two streams. This very thin layer sheet is termed as the shock circle. The authors claimed that this 2-D model calculation were simpler to perform then the previously used 1-D models with better accuracy. The entrainment ratio values predicted by the model matched more accurately with the experimental results (of Huang et al. 1999) compared to 1-D model used by the later. The largest deviation observed in predicting the entrainment ratio was $11 \%$. Using the shock circle model concept, Zhu and Li (2009) further used a novel model for 2-phase ejector performance evaluation for wet and dry working fluids at the chocked (critical) mode.

Furthermore, Wang et al. (2009) have experimentally assessed an ejector cooling system with thermal pumping by a multi-functional generator. The authors found the COP up to 0.45 when operated at higher evaporator temperatures using R365mfc. To encounter the ejector geometry effects, Yan et al. (2012) used a CFD based model with the experimental investigation of the same. The ejector area ratio (mixing constant area/nozzle throat area) and the nozzle exit position were the dominating geometrical parameters to improve the ejector entrainment ratio. Śmierciew et al. (2014) has experimentally studied the generator and condenser temperature effects on a solar heat operated ejector refrigeration system with refrigerant isobutene. The COP varied between 0.15 to 0.2 . Eldakamawy et al. (2017) used retrograde (dry) refrigerants and investigated the ejector refrigeration system and found that the use of dry refrigerant promising in the ejector based systems. Further, Varga et al. (2017) have experimentally reported a small-scaled ejector refrigerator utilizing solar heat installed at Portugal. $1.5 \mathrm{~kW}$ ejector with R600a refrigerant were considered in the study. The thermal 
COP was varying between $0.15-0.40$ with 4.6 average mechanical COP. Recently, Narimani et al. (2019). Performed numerical and experimental study to investigate the generator pressure effect in the R245fa based ejector refrigeration system. The authors found that ejector operates at single chocking mode and double chocking mode operations before and after an optimum generator pressure respectively. Furthermore, more studies have been carried out to study the COP of ejector refrigeration systems with various refrigerants and found that the environmental friendly refrigerants have lower COP compared to the obsoleting refrigerants (Gil and Kasperski, 2015; Shestopalov et al. 2015; Zhang et al. 2015).

Several studies on optimization of ejector refrigeration systems are reported in literature. Dai et al. (2009) optimized the ejector refrigeration cycle combined with the Rankine power cycle using genetic optimization algorithm. Chen et al. (2014) numerically presented the optimum COP with variation in the generator temperature keeping evaporator and condenser temperature to a fixed value. Also, the optimum ejector entrainment ratio and area ratio with variation in the condenser temperature is obtained using R123 and R141b as the refrigerants. Further to this, Sadeghi et al. (2015) have performed the exergo-economic study and the multi-objective optimization using genetic optimization algorithm of an ejector refrigeration system using $\mathrm{R} 141 \mathrm{~b}$. The concept and equations of 2-dimensional model were utilised to simulate the ejector component. The system temperatures were adjusted by the algorithm to optimize the exergy efficiency and the product unit cost. The authors have considered the exergy destruction cost to evaluate the total cost of the system as the ejector is found as the leading exergy destructing component of such systems. Sanaye et al. (2019) optimized a system combined of vapour-vapour ejector cycle and a liquid-vapour ejector cycle from energy, exergy, economic and environment viewpoints. With 5 design variables and 2 conflicting objective functions, the authors obtained about $18 \%$ performance coefficient improvement and $8 \%$ lower annual cost. 
The useful concluding information from the above reviews are: a) the concept of 2-D shock circle model is found more practical in assessing the ejector performance as it considers the viscosity effects and hence the non-uniform distribution of velocity in $y-y$ plane of mixing chamber, b) very fewer studies on the multi-objective optimization of conventional ejector refrigeration system. The multi-objective optimization using COP and cost as objectives is also not found in literature, c) exergy destruction is mostly highest in the ejector and can be reduced by considering the cost associated with this exergy destruction (exergoeconomic study) which is considered by Sadeghi et al. (2015) only as per our foremost knowledge, d) COP optimization with operating temperatures as design variables and use of newly developed optimization algorithms can explore more improved operating conditions to the ejector refrigeration systems.

The present work focuses on the multi-objective optimization of an ejector refrigeration system considering COP and TAC as two objective functions. For low-grade energy driven systems (such as ejector refrigeration systems, absorption refrigeration system), the COP values are quite lower (main contributing reason for not penetrating into the market). So, this makes the COP, a very important performance parameter to be enhanced to reduce the input energy requirement for the desired output. Secondly, the TAC value includes components initial cost, operating cost, and the cost associated with the exergy destruction in the components (Exergo-economic analysis). By doing this, reduction in the TAC value will improve the second law based performance of the system as well. Even, TAC is also a major factor for the system's market opportunities. Further, COP and TAC are found conflicting objectives (if one improves, other has to degrade). This seeks for the need of multi-objective optimization wherein the input parameters (decision variables) improved in such a way that both the objectives can take optimum value. 
The main novelty of this work is to present the multi-objective optimization of an ejector refrigeration system using a novel multi-objective heat transfer search (HTS) algorithm with the thermo-economic approach. The consideration of COP and the total annual cost (TAC) of the system as two objective functions (thermo-economic) adds novelty to this work further as the optimized outputs can contribute in trading-off the ejector refrigeration system between thermal performance (COP) and the economy. The COP is selected as it is the main reason for the inability of such low-grade energy-driven systems to penetrate the market. Secondly, the TAC value considers the economic as well as the second law based performance by taking the exergy destruction costs into the account. The outcome of the thermo-economic optimization is presented in the form of Pareto front. Additionally, the sensitivity analysis of the objectives and the exergo-economic analysis at the optimal condition are also presented. The concept and equations of 2-D shock circle model is used to simulate the ejector component in MATLAB tool. A dry refrigerant R245fa with positive slope of the saturated vapour line, is used as a working fluid and therefore, the working fluid will not condense in the ejector (Chunnanond and Aphornratana, 2004). This hydrofluorocarbon (HFC) refrigerant is selected as it has good thermo-physical properties with zero potential to ozone depletion (Shestopalov et al. 2015).

\section{System Description and Modelling}

This section describes the ejector refrigeration system and the models for thermodynamic and the exergo-economic analyses.

\subsection{System Description}

The low-grade energy-driven ejector refrigeration system is shown in Fig. 1. It consists of an ejector, generator, evaporator, condenser, expansion valve and pump. Exhaust gases from an IC engine is considered as the heat source to generator wherein the working fluid (R245fa) is vaporised to generator temperature. An ejector comprises of a primary nozzle, 
suction zone, mixing zone and a diffuser as shown in Fig. 2. The high pressure saturated vapour generated in the generator will enter the ejector as the primary flow stream. The converging-diverging nozzle will impart supersonic velocity to the primary stream (chocked at the nozzle throat) and hence the pressure at the nozzle exit will be low. This low pressure will form the suction chamber for the secondary fluid stream (low pressure vapour refrigerant) from the evaporator. These primary and secondary vapour streams will mix at the effective area where the secondary stream will get chocked. The mixed flow will then undergo a shock wave while moving through the constant area section. This leads to increase in the pressure and the velocity becomes subsonic (Huang et al. 1999). This stream will exit the ejector at the condenser pressure after further increasing its pressure in the diffuser section. The saturated liquid stream from the condenser will separate itself into two streams. One stream will be pumped to the generator where it is heated to the vapour state (primary stream). The second stream will be expanded to the evaporator pressure after passing through the expansion valve. In the evaporator, this secondary stream will get converted to the vapour state after receiving heat of the cooling load. The exhaust gas from an IC engine is considered as the heat source in the generator.

\subsection{Thermal Modelling}

Thermal modelling and simulation of the system is carried out in MATLAB tool. The following assumptions are considered for the system simulation (Zhu et al. 2007, Huang et al. 1999, Sadeghi et al. 2015):

- Steady state simulation with $25^{\circ} \mathrm{C}$ and $100 \mathrm{kPa}$ as ambient conditions.

- The condition at the outlet of the generator and evaporator is saturated vapour while the condition at the outlet of the condenser is saturated liquid.

- Frictional pressure drops in the pipes are neglected, typically calculated at the detailed design stage. 
- Adiabatic inner walls of the ejector.

- Kinetic energies of the entering primary and secondary streams as well as the exit mixed stream from the diffuser are negligible.

- The secondary stream flow gets chocked and becomes critical at the effective a-a area where mixing starts.

- The pressure of the entering secondary flow stream is assumed equal to the evaporator pressure.

- Refrigerant feeding pump which pumps the refrigerant from the condenser to the generator remains cavitation-free.

- The mechanical efficiency of pump is considered as $75 \%$.

- For the simplicity in simulation, the isentropic efficiencies are assumed for considering the frictional losses. Isentropic efficiencies of primary flow, secondary flow and the flow in the diffuser are considered as $0.95,0.85$ and 0.90 respectively.

\subsubsection{Ejector model}

In this work, the ejector component is modelled considering the concepts of shock circle model proposed by Zhu et al. (2007). This model predicts the ejector performance by considering the two-dimensional velocity distribution (exponential) in the constant area mixing chamber. This will include the viscosity effects near the wall in the mixing chamber. Table 1 shows the equations used for the ejector component modelling. Also, the simulation flowchart, which focuses on the ejector component modelling, is shown in Fig. 3. The thermo-physical properties $C_{p}, \gamma$ and $R_{g a s}$ are considered to be temperature dependent and hence they are taken from REFPROP fluid library in MATLAB. The output parameters from the ejector are temperature (condenser temperature) and pressure of mixed flow, mass flow rates of primary and secondary flow streams and the constant area section diameter. 


\subsubsection{Energy analysis}

Steady state energy analysis is performed using following energy balance for a system component:

$\dot{Q}-\dot{W}=\sum_{i} \dot{m}_{i} h_{i}-\sum_{e} \dot{m}_{e} h_{e}$

where $h, \dot{Q}$ and $\dot{W}$ are the state enthalpy, heat transfer rate and work transfer rate, respectively. These energy balance equations for generator, evaporator, condenser and pump are listed in Table 2.

\subsubsection{Exergo-economic analysis}

The analysis of any thermal system is worthy when it is carried out from both thermodynamic and economic point of view. Further, in order to consider the second law of thermodynamics (exergy and irreversibility), the cost associated with the energy destruction is accountable. Keeping this point in mind, the exergo-economic analysis is performed for the system based on the procedure given by Lazzaretto and Tsatsaronis (2006). There are two kind of components in the system: productive and dissipative (Lazzaretto and Tsatsaronis 2006). In present system, the cooling unit consist of evaporator as productive component while condenser and expansion valve as its dissipative components. The total annual cost (TAC) for the system from exergo-economic analysis can be equated as (Sadeghi et al. 2015):

$\operatorname{TAC}(\$ / y)=\sum \dot{Z}_{k}+\sum \dot{C}_{D, k}+\dot{C}_{f}$

where $\dot{Z}_{k}, \dot{C}_{D, k}$ and $\dot{C}_{f}$ are the cost rates of component investment, component exergy destruction and system fuel. $\dot{Z}_{k}$ can be determined by:

$\dot{Z}_{k}=Z_{k} \times C R F \times M F$

where $Z_{k}, C R F$ and $M F$ are the component investment (capital) cost, capital recovery factor and the maintenance factor, respectively. The component capital cost equations and their finding procedure is adopted from the work of Misra et al. (2003) and Sadeghi et al. (2015). 
Further in exergo-economic assessment, the cost rate associated with exergy destruction in the component $\left(\dot{C}_{D, k}\right)$ can be given as:

$\dot{C}_{D, k}=u_{f, k} \times \dot{E}_{D, k}$

Here $u_{f, k}$ is the unit cost of the component fuel source and $\dot{E}_{D, k}$ is the exergy destruction rate within the component. The exergy rate of a flowing stream is given by:

$\dot{E}_{k}=\dot{m}_{k}\left(\left(h_{k}-h_{0}\right)-T_{0}\left(s_{k}-s_{0}\right)\right)$

Here subscript $\mathrm{k}$ and 0 represents particular component and reference state conditions which are considered as $25{ }^{\circ} \mathrm{C}$ and $100 \mathrm{kPa}$. Table 3 lists the exergy destruction rate for each component of this system which is obtained by applying exergy balance. Further to evaluate $u_{f, k}$, we have:

$u_{f, k}=\dot{C}_{f, k} / \dot{E}_{f, k}$

Where suffix $f$ represent the fuel source of particular component. To evaluate these exergybased cost rates, the cost balance equation formulation is needed for each component. The general cost balance equation is as:

$\sum \dot{C}_{i n, k}+\dot{Z}_{k}+\dot{C}_{Q, k}=\sum \dot{C}_{e x, k}+\dot{C}_{W, k}$

The above equation makes us to understand that the sum of rates of the exergy cost of the leaving streams is equal to the summation of rates of the exergy cost of incoming streams and the net cost (capital and operational) of a particular component. This cost balancing is applied to each component and presented in Table 4. The total number of exergy streams in a system will always be higher (in general) compared to the total number of components and hence the numbers of cost balance equations. These require auxiliary equations to equalise their number. Table 5 lists the auxiliary equations for this system (Sadeghi et al. 2015). These auxiliary equations are obtained by applying F-principle and P-principle to the components. These principles are described in detail by Lazzaretto and Tsatsaronis (2006). 


\subsection{Model validation}

The ejector refrigeration system model is validated with the results obtained for similar system from the work of Sadeghi et al (2015) operating with R141b refrigerant. The results of the present model (Table 9(a)) match significantly with the results in the reference within $3 \%$ error hence validate the system model. As the thermal modelling focuses mainly on the ejector component, its validation with the experimental results available in the work of Huang et al. (1999) is shown in Table 9(b). In this validation, for different nozzle geometries and various operating temperatures (with $\mathrm{R} 141 \mathrm{~b}$ as refrigerant), two ejector output parameters are compared. These are entrainment ratio $\left(\dot{m}_{s} / \dot{m}_{p}\right)$ and the area $\operatorname{ratio}\left(D_{e 2} / D_{t}\right)^{2}$. The values obtained from the present model agree well with the experimental results of the same within $10 \%$ deviation. This \% error limit is acceptable in an engineering analysis.

\section{Design variables, Objective functions and Constraints}

The multi-objective based optimization is performed for the system using HTS algorithm. The selected design (decision) variables, objective functions and the associated constraints are discussed in this section.

\subsection{Design variables and associated constraints}

In this ejector-based thermal system, operating temperature in the components significantly influences the system performance. Three decision variables namely evaporator temperature, condenser temperature and generator temperature are selected for the optimization. The selected ranges of these design variables and the constraints are listed in Table 6. Ecological function (ECF), the difference between net heat supplied and the entropy generation rate, is also considered as an ecological parameter. The physical importance of ECF is to favour our physical environment by controlling the entropy generation from the system operation (Ahmadi et al. 2014). ECF is considered as a constraint with a fixed value of $11 \mathrm{~kW}$. 


\subsection{Objective functions}

As per thermos-economic criteria, a thermal objective namely the coefficient of performance (COP) of the system and an economic objective namely the total annual cost (TAC) of the system, are selected as the objective functions. Coefficient of performance is to be maximised while TAC is set to be minimized.

\section{Heat transfer search (HTS) algorithm and its multi-objective form}

Heat transfer search is an evolutionary algorithm created by Patel and Savsani (2015). This HTS algorithm mimics the law of thermodynamics and heat transfer which state that every system in the universe always tries to attain thermal equilibrium with its surrounding through various heat transfer processes. Like other evolutionary algorithms, HTS is also a population based algorithm. The search process of HTS algorithm is made up of 'conduction phase', 'convection phase' and 'radiation phase'. In the optimization algorithm, heat transfer terms namely molecules are treated as population, temperature of the molecules are treated as design variable, and energy level of the molecules are treated as objective function value of the population.

The HTS algorithm initiates with the random solution generation for the considered population. This population then updates through the execution of any one of the phases mentioned above until the predefined termination criteria is reached. During each generation, only one of the above-mentioned phase will execute to update the population. The execution of any of the phase to update the population depends on the execution probability associated with that phase. In the HTS algorithm, equal probability is assigned to each 3 phases involved during the course of optimization. This equal probability is decided by a random number which varies between 0 and 1 . Further, the algorithm also incorporates the greedy selection components which ensure that only improved solutions are accepted during the course of 
optimization. The elitism concept is also implemented in the algorithm to achieve the better output. The detailed description of each of the phase of the HTS algorithm along with its mathematical formulation is available in the pioneer work of Patel and Savsani (2015).

The success of any optimization algorithm depends on the proper balance between the exploration and exploitation during the search process. The search process of the HTS algorithm consist of three phase and each phase build with two different search mechanism which balance the exploration and exploitation during search process. The search processes of HTS algorithm design in such a way so that during early generations each phase explores the search space, while in the second half each phase exploits the search space. In this way, the HTS algorithm balances the exploration and exploitation of an entire search process. However, the computational time of the proposed algorithm is more due to its search mechanism.

Multi-objective heat transfer search (MOHTS) algorithm is a multi-objective variant of the HTS algorithm aimed to solve multi/many-objective problems (Patel et al. 2017, Patel 2018, Raja et al. 2017, Patel and Raja 2019). MOHTS algorithm adopts a non-dominated sorting process to generate the Pareto solutions. The algorithm identifies the non-dominated solutions and keep it in the algorithm's external archive. During each generation, the external archive of the MOHTS is updated with the help of the $\varepsilon$-dominance method which inspects the domination of the solution. The dominated solutions are eliminated from the external achieves and remaining non-dominated solutions within the external achieves are used to generate the Pareto front. The detail description and working of the MOHTS algorithm available in literature (Patel et al. 2017, Raja et al. 2017, Patel 2018, Patel and Raja 2019). 


\section{Application Example}

The exhaust gas from an IC engine is considered as the generator heat source in the system. The constant heat input of $33 \mathrm{~kW}$ at $225{ }^{\circ} \mathrm{C}$ exhaust gas temperature and $0.25 \mathrm{~kg} / \mathrm{s}$ mass flow rate is considered. To simplify the simulation process, the cooling water stream is assumed to enter and leave the condenser at $\left(T_{c r}-5\right){ }^{\circ} \mathrm{C}$ and $\left(T_{c r}-2\right){ }^{\circ} \mathrm{C}$. Similarly, the cooling load (chilled water) stream is assumed to enter and leave the evaporator at $\left(T_{\text {evap }}+8\right){ }^{\circ} \mathrm{C}$ and $\left(T_{\text {evap }}+3\right){ }^{\circ} \mathrm{C}$ (Sadeghi et al. 2015). The isentropic efficiencies of primary and secondary stream flows are taken as $95 \%$ and $85 \%$ while the diffuser isentropic efficiency is considered to be $90 \%$ (Zhu et al. 2007). The primary nozzle throat diameter and nozzle exit diameter are taken as $9.5 \mathrm{~mm}$ and $19 \mathrm{~mm}$, respectively. For economic analysis, interest rate of $15 \%$, maintenance factor of 1.06 and system's expected life of $20 \mathrm{y}$ are considered. Further, the unit cost of electricity for the pump and the heat source to the generator and are taken as 10 \$/GJ and 23.59 \$/GJ respectively (Sadeghi et al. 2015). Finally, the exergy cost rates of water streams entering the evaporator and condenser are taken as zero.

\section{Results and Discussion}

The results obtained from the multi-objective optimization of the ejector based refrigeration system using HTS algorithm is presented in this section.

\subsection{Multi-objective optimization}

Considering COP and TAC as two objectives simultaneously, the optimized result in form of Pareto front is presented in Fig. 4. All the points in the Pareto front are the optimal solutions. Both COP and TAC are showing the conflicting behavior as the maximized COP solution point has the maximum value of TAC (which is to be minimized) and vice versa. The optimal point A has the minimum optimum TAC $(25,657 \$ / y)$ with minimum optimum COP (0.26) and the optimal point $\mathrm{E}$ has the maximum optimum COP (0.35) but with 
maximum optimum TAC $(26,594 \$ / y)$. Based on this behavior, one can select either point $\mathrm{E}$ or point $\mathrm{A}$ as the optimum design solution if the only objective to be focused is COP or TAC respectively. $4 \%$ and $31 \%$ is the increment observed in the optimal values of TAC and COP upon moving from $\mathrm{A}$ to $\mathrm{E}$ respectively. Apart from the end points $\mathrm{A}$ and $\mathrm{E}$, three more optimal points are chosen for the study (B, C and D). The design variables and the objective function values at all five optimal points are listed in Table 7. The evaporator and condenser temperature varies significantly from point $\mathrm{A}$ to $\mathrm{E}$ while generator temperature has insignificant scattering from A to E. This observation states that the former two temperatures dominantly produce the conflicting effect on the objective functions compared to the generator temperature. Further, the ideal (best) optimal solution that can be obtained by considering equal weightage of both the objective functions is point $\mathrm{O}$ while the least desirable solution (non-ideal) is point $\mathrm{N}$. Therefore, an optimal point nearest to the ideal point should be selected in order to consider COP and TAC simultaneously. Among available solution points, point $\mathrm{B}$ is the nearest to the ideal solution obtained from this multi-objective optimization. Finally, one can conclude from a Pareto front that the decision-maker can select any of the optimal design points according to the priority of the objective functions.

\subsection{Sensitivity analysis}

Sensitivity analysis highlights the behavior of objective functions upon variation in design variable values from their optimum points. The observations from sensitivity analysis can help the decision maker in adjusting any of the design variables value from its value at the optimal solution while implementing the optimal design (Jaluria, Y. 2007). Here the design variables are varied individually for all five selected optimal solutions (A to E) and the results are plotted in Fig. 5. Fig. 5 (a) shows the effect of varying the generator temperature from its optimal value within its range. It demonstrates that with increase in the generator temperature from its optimal point, the COP decreases while TAC initially increases and then 
decreases. The initial rise in TAC is less significant than the later decrement. On moving from optimal point A to E, TAC is almost unchanged initially and decreases afterwards as generator temperature increases. These observations can help the decision-maker in knowing that how sensitively the generator temperature variation changes the objective functions. Physically, the decrease in COP is because of rise in heat supplied for constant refrigeration effect as evaporator and condenser temperatures are unaltered (from their optimal point values). Further, it is found that the generator is the second leading component to the exergy destruction (Fig. 8) and as the temperature differential in the generator component (between the constant heat source temperature and the generator temperature) decreases with rise in the generator temperature, the exergy destruction in the generator decreases. Due to this, there is also noticeable drop in the exergy destruction cost (compared to the other capital and operating costs) of the generator and hence the drop in TAC.

Fig. 5 (b) shows the effect of variation in the evaporator temperature from its optimal values at all 5 different optimal points (A to E). With rise in the evaporator temperature, both objectives increases. The varying range of COP is almost same for all optimal points (A to E) while the varying range of TAC becomes costlier from A to E. These results can suggest the decision-maker to adjust the evaporator temperature according to the prior objective among the two. Physically, these trends for both the objective functions are due to increase in the refrigeration capacity at constant condenser and generator side parameters. This uplift in the refrigeration capacity will increase the $\mathrm{COP}$ and $\mathrm{TAC}$ both. The TAC increase can be understood by the fact that the heat exchanger (evaporator) size needs to be larger to accommodate the rise in the refrigeration capacity. This will increase the capital cost of the evaporator and hence the TAC.

The effect of variation in the condenser temperature from its optimal point value is shown in Fig. 5 (c). With increase in the condenser temperature, both objective functions 
show decrement wherein the COP reduction is almost insignificant compared to the reduction in TAC. This suggests that compared to $\mathrm{COP}$, the TAC is more sensitive to the condenser temperature. Further, in contrary to the above evaporator temperature variation effects, here the varying range of TAC (for all 5 optimal points A to E) is almost same and it is not so for the varying range of COP. Physically, the reduction in the working fluid mass flow rate demands for the lower sized condenser component and will decrease the exergy destruction as well. This leads to significant TAC reduction. Finally, one can conclude from this sensitivity analysis that (a) for an optimal point (any among A to E), the TAC is affected significantly by all 3 design variables while the COP gets affected by the evaporator and generator temperature, (b) on moving from A to E, COP is sensitive to condenser temperature while TAC is sensitive to generator and evaporator temperatures.

The consideration of exergy destruction cost plays significant role in deciding the total cost value of the system. To justify this with numbers, further detailed analysis is carried out at optimal point B. In case of varying the evaporator temperature, for 6 Kelvin rise in the evaporator temperature (from $278 \mathrm{~K}$ to $285 \mathrm{~K}$ ) and keeping condenser and generator temperature at their optimal values, the total capital cost indeed gets decreased by $226 \$$ year but the total exergy destruction cost gets increased by 1007 \$/year. Among this 1007 \$/year rise in exergy destruction cost, the ejector component exergy destruction cost shows 240 $\$$ year increase. Hence, this trend leads to overall rise in the TAC. Further, In case of varying the condenser temperature, for 7 Kelvin rise in the evaporator temperature (from $306 \mathrm{~K}$ to $213 \mathrm{~K})$ and keeping evaporator and generator temperature at their optimal values, the total capital cost gets increased by 323 \$/year but the total exergy destruction cost gets decreased by $1955 \$$ year. Among this $1955 \$$ /year drop in exergy destruction cost, the ejector component exergy destruction cost shows $682 \$ /$ year decrement. Hence, this trend leads to overall drop in the TAC. 
From the above analysis, one can note that the exergy destruction cost considerations (exergo-economic concept) in such systems where the highly irreversible components such as ejector and generator are present, plays a significant role in the objective function value (TAC) change when the design variables are varied from their optimum values. This is why the sensitivity analysis on the optimization results is necessary.

\subsection{Effect of nozzle throat diameter and Ecological function}

Three different nozzle throat diameters are considered by keeping the nozzle exit diameter unchanged. The Pareto fronts in all 3 cases are plotted in Fig. 6. It shows that with increase in nozzle throat, the Pareto shifts upward, i.e., for same TAC, the COP improves with the throat diameter. Moreover, for same COP, the TAC value increases with decrease in the throat diameter. The increase in the primary stream flow rate with nozzle throat diameter is the reason for this observed trend. Also, this behavior tells that the exergy destruction within the ejector can be reduced by increasing the nozzle throat diameter. Further, the ecological function $(\mathrm{ECF})$ is varied to see its effect on the optimization results. The Pareto fronts obtained for 3 different values of ECF are shown in Fig. 7. High ECF value favors the COP objective significantly. For same net heat input to the system, low ECF value indicates high exergy destruction in the system and hence the high TAC. Therefore, from ecology point of view, this ECF consideration can lead to better optimization solutions.

\subsection{Exergo-economic analysis results}

The system performance at the optimal point B (nearest to the ideal solution) is investigated from exergo-economic point of view. Table 8 summarizes the state properties and the cost values at each stage of the system. The main product output from the current system is the water stream being chilled in the evaporator and therefore, the product unit cost $\left(u_{12}\right)$ at state point 12 is found to be $53.8 \$ /$ GJ. The improvement in the exergy efficiency can decrease this product unit cost. The exergy destruction rate and the corresponding destruction 
cost rate of each component is presented in Fig. 8 and Fig. 9, respectively. From total exergy input of $5.24 \mathrm{~kW}, 74.4 \%(3.9 \mathrm{~kW})$ is the total exergy destruction in the system, $15.1 \%(0.79$ $\mathrm{kW})$ is the exergy loss in the system and the rest $10.5 \%(0.55 \mathrm{~kW})$ is the system exergy output. Only $10.5 \%$ utilization of the input exergy is due to the highly irreversible components such as ejector and the generator. Also, $15.1 \%(0.79 \mathrm{~kW})$ exergy loss takes place in the condenser due to heat rejection at a temperature higher than the surrounding temperature. In addition to this, the highest exergy destruction of $\sim 2 \mathrm{~kW}(38 \%)$ is in the ejector component followed by the generator with $1.21 \mathrm{~kW}(23.1 \%)$ exergy destruction rate. As ejector undergoes irreversible processes such as mixing, friction and the shock wave, it shows the highest exergy destruction while the high temperature difference is the reason for significant exergy destruction in the generator. Concluding this, the exergy efficiency at the optimal point B is found to be $10.5 \%$. From Fig. 9, the total exergy destruction cost at the optimal point B is $3846.2 \$ / y$ with ejector as the highest contributor followed by the cooling unit. Table 7 give the TAC at B as $25903 \$$ y. The cooling unit (evaporator, condenser and expansion valve) cost rate is 1379 \$/year. Upon including the initial cost of components to this destruction cost, the cooling set is having the highest TAC.

\subsection{Economic comparison without and with sub-cooling arrangement}

The cavitation in the pump can be avoided by using the sub-cooling arrangement that subcools the refrigerant leaving the condenser below saturation temperature. This sub-cooling will not allow the bubbles to get formed when the refrigerant will enter the pump and the assumption of cavitation-free pump can be justified. To consider the economic effect in the existing system with sub-cooling arrangement, a heat exchanger as sub-cooler is added before pump. It is assumed that sub-cooling of $5{ }^{\circ} \mathrm{C}$ is required to avoid the cavitation (Sokolov and Hershgal, 1991). The cost results with this consideration are compared with the studied system's cost values at the best optimal point B. It is found that the rise in the TAC is 973 
$\$ /$ year (3.75\% rise). Among this total increase of $973 \$$ year, capital cost rises by 743 \$ year, operating cost rises by $156 \$ /$ year and the exergy destruction cost is increased by $74 \$ /$ year.

\subsection{Effect of pump isentropic efficiency on objectives}

So far in the work, mechanical efficiency of 0.75 is considered in order to cover hydraulic and frictional losses. For low viscous refrigerant like R245fa, the additional pump work required due to entropy change (non-isentropic) condition can be considered using isentropic efficiency of the pump. Keeping this in mind, the overall pump efficiency can be considered as $\eta_{p u m p}=\eta_{m, p} \times \eta_{s, p}$ (where $\eta_{m, p}$ and $\eta_{s, p}$ are mechanical and isentropic efficiencies of pump respectively). The isentropic efficiencies considered for pumping R245fa are $0.4,0.5$ and 0.6 (Surindra et al., 2019). At optimal point B, Table 10 shows that pump work rises significantly for chosen isentropic efficiencies compared to $100 \%$ isentropic efficiency of pump. But it is notable that there is negligible change in the COP objective even when pump isentropic efficiency is $40 \%$. This is due to the low-grade heat driven system where pump work is negligible compared to generator input heat. Further, in case of TAC, for $40 \%$ isentropic efficiency, the change in $\mathrm{TAC}$ is $1.1 \%$ which is somehow significant as running cost of less efficient pump is higher.

\section{Conclusion}

Thermodynamic modelling and multi-objective considered optimization of an exhaust heat-driven ejector refrigeration system is performed in this work. A newly-developed and an efficient heat transfer search (HTS) optimization algorithm is used. The coefficient of performance and the total annual cost of the system are considered as the objective functions (thermos-economic consideration) while the system temperatures are selected as the design variables. In order to consider the cost of exergy destruction as a part of the total cost, the exergo-economic approach is adopted during economic evaluation. This exergo-economic 
approach helps in knowing the trade-off between the investment costs and the exergy destruction cost of the system components and hence helps in the real cost evaluation. The Pareto frontier obtained as a result of the multi-objective optimization gives the optimum design points (solutions) to the decision-maker who can implement any of the optimum design points based on the requirement and the priority of the objective functions. Also, compared to generator temperature, evaporator and condenser temperatures produces more conflicting effect between both the objective functions i.e. COP and TAC. The evaporator, condenser and generator temperatures take respective values of $274.6 \mathrm{~K}, 308.5 \mathrm{~K}$ and 351.6 $\mathrm{K}$ at the optimal point $\mathrm{B}$ which is found closest to the ideal point in the Pareto front. The objectives COP and TAC take respective values of 0.3 and $25903 \$ / y$ at this best optimal point. Further, the sensitivity analysis at 5 selected optimal points reveals that the TAC is affected significantly by all 3 design variables while evaporator and generator temperature affects significantly to COP as compared to condenser temperature. The exergo-economic results at optimal points $B$ reveals that the product unit cost is $53.8 \$ / G J$ and can be further decreased by increasing the exergetic efficiency of the system $(10.5 \%)$. This can be achieved by reducing the exergy destruction in the ejector and the generator as they are found as the leading contributors for the same at the optimum condition.

\section{Conflict of Interest:}

The authors declare that they have no conflict of interest.

\section{References}

Ahmadi MH, Ahmadi MA, Mehrpooya M, Hosseinzade H, Feidt M (2014) Thermodynamic and thermo-economic analysis and optimization of performance of irreversible fourtemperature-level absorption refrigeration. Energy Conversion and Management 88:1051-1059. 
Chen J, Havtun H, Palm B (2014). Investigation of ejectors in refrigeration system: Optimum performance evaluation and ejector area ratios perspectives. Applied Thermal Engineering 64(1-2):182-191.

Chen W, Liu M, Chong D, Yan J, Little AB, Bartosiewicz Y (2013). A 1D model to predict ejector performance at critical and sub-critical operational regimes. International Journal of Refrigeration 36(6):1750-1761.

Chunnanond K, Aphornratana S (2004). Ejectors: applications in refrigeration technology. Renewable and Sustainable Energy Reviews 8(2):129-155.

Dai Y, Wang J, Gao, L (2009). Exergy analysis, parametric analysis and optimization for a novel combined power and ejector refrigeration cycle. Applied Thermal Engineering 29(10):1983-1990.

Eldakamawy, M. H., Sorin, M. V., \& Brouillette, M. (2017). Energy and exergy investigation of ejector refrigeration systems using retrograde refrigerants. International Journal of Refrigeration, 78, 176-192.

Gil, B., \& Kasperski, J. (2015). Efficiency analysis of alternative refrigerants for ejector cooling cycles. Energy conversion and management, 94, 12-18.

Huang BJ, Chang JM, Wang CP, Petrenko VA (1999). A 1-D analysis of ejector performance. International Journal of Refrigeration 22(5):354-364.

Jaluria, Y. (2007). Design and optimization of thermal systems. CRC press.

Lazzaretto A, Tsatsaronis G (2006). SPECO: a systematic and general methodology for calculating efficiencies and costs in thermal systems. Energy 31(8-9):1257-1289.

Liu J, Wang L, Jia L (2017). A predictive model for the performance of the ejector in refrigeration system. Energy Conversion and Management 150:269-276.

Misra RD, Sahoo PK, Sahoo S, Gupta A (2003). Thermo-economic optimization of a single effect water $/ \mathrm{LiBr}$ vapours absorption refrigeration system. International Journal of Refrigeration 26(2):158-169.

Narimani, E., Sorin, M., Micheau, P., \& Nesreddine, H. (2019). Numerical and experimental investigation of the influence of generating pressure on the performance of a one-phase 
ejector installed within an R245fa refrigeration cycle. Applied Thermal Engineering, 157, 113654.

Patel VK (2018). An efficient optimization and comparative analysis of ammonia and methanol heat pipe for satellite application. Energy Conversation and Management 165:382-395.

Patel VK, Raja BD (2019). A comparative performance evaluation of the reversed Brayton cycle operated heat pump based on thermo-ecological criteria through many and multi objective approaches. Energy Conversation and Management 183:252-265.

Patel VK, Savsani VJ (2015). Heat transfer search (HTS): A novel optimization algorithm. Information Sciences 324:217-246

Patel VK, Savsani VJ, Mudgal A (2017). Many-objective thermodynamic optimization of Stirling heat engine. Energy 125:629-42

Raja BD, Jhala RL, Patel VK (2017). Many-objective optimization of cross-flow plate-fin heat exchanger. International Journal of Thermal Sciences 118:320-39

Sadeghi M, Mahmoudi SMS, Saray RK (2015). Exergoeconomic analysis and multiobjective optimization of an ejector refrigeration cycle powered by an internal combustion (HCCI) engine. Energy Conversion and Management 96:403-417.

Sanaye S, Emadi M, Refahi A (2019). Thermal and economic modeling and optimization of a novel combined ejector refrigeration cycle. International Journal of Refrigeration 98:480493.

Shestopalov, K. O., Huang, B. J., Petrenko, V. O., \& Volovyk, O. S. (2015). Investigation of an experimental ejector refrigeration machine operating with refrigerant R245fa at design and off-design working conditions. Part 1. Theoretical analysis. international journal of refrigeration, 55, 201-211.

Śmierciew, K., Gagan, J., Butrymowicz, D., \& Karwacki, J. (2014). Experimental investigations of solar driven ejector air-conditioning system. Energy and buildings, 80, 260-267. 
Sokolov, M., \& Hershgal, D. (1991). Enhanced ejector refrigeration cycles powered by low grade heat. Part 3. Experimental results. International journal of refrigeration, 14(1), 2431.

Surindra, M. D., Caesarendra, W., Prasetyo, T., \& Mahlia, T. M. I. (2019). Comparison of the utilization of $110^{\circ} \mathrm{C}$ and $120^{\circ} \mathrm{C}$ heat sources in a geothermal energy system using Organic Rankine Cycle (ORC) with R245fa, R123, and mixed-ratio fluids as working fluids. Processes, 7(2), 113.

Tashtoush B, Alshare A, Al-Rifai S (2015). Performance study of ejector cooling cycle at critical mode under superheated primary flow. Energy Conversion and Management 94:300-310.

Varga, S., Oliveira, A. C., Palmero-Marrero, A., \& Vrba, J. (2017). Preliminary experimental results with a solar driven ejector air conditioner in Portugal. Renewable energy, 109, 8392.

Wang, J. H., Wu, J. H., Hu, S. S., \& Huang, B. J. (2009). Performance of ejector cooling system with thermal pumping effect using R141b and R365mfc. Applied Thermal Engineering, 29(10), 1904-1912.

Yan, J., Cai, W., \& Li, Y. (2012). Geometry parameters effect for air-cooled ejector cooling systems with R134a refrigerant. Renewable energy, 46, 155-163.

Zhu Y, Cai W, Wen C, Li Y (2007). Shock circle model for ejector performance evaluation. Energy Conversion and Management 48(9):2533-2541.

Zhu Y, Li Y (2009). Novel ejector model for performance evaluation on both dry and wet vapors ejectors. International Journal of Refrigeration 32(1):21-31.

Zhang Z, Tong L, Chang L, Chen Y, Wang X, Knuth KH (2015) Energetic and Exergetic Analysis of an Ejector-Expansion Refrigeration Cycle Using the Working Fluid R32. Entropy 17:4744-4761. 


\section{Figure Caption}

Fig. 1: Schematic diagram of ejector refrigeration system

Fig. 2: Ejector component

Fig. 3: Simulation Flowchart

Fig. 4: Pareto frontier from multi-objective optimization

Fig. 5: Sensitivity of objective function to (a) generator temperature (b) evaporator temperature (c) condenser temperature

Fig. 6: Effect of nozzle throat diameter on Pareto solutions

Fig. 7: Effect of Ecological function (ECF) on Pareto solutions

Fig. 8: Exergy destruction rate in system components at optimal point B

Fig. 9: Exergy cost rate in system components at optimal point B

\section{$\underline{\text { Table Caption }}$}

Table 1: Ejector component modelling (Zhu et al. 2007, Sadeghi et al. 2015)

Table 2: Energy analysis based governing equations

Table 3: Exergy destruction in components

Table 4: cost balance in components

Table 5: Auxiliary equations for components

Table 6: Design variable ranges and constraints

Table 7: Optimal parameters at selected design points (A-E)

Table 8: State properties and costs at optimal point B

Table 9: Thermal model validations (a) Ejector system model validation, (b) Ejector component model validation

Table 10: Effect of pump isentropic efficiency 


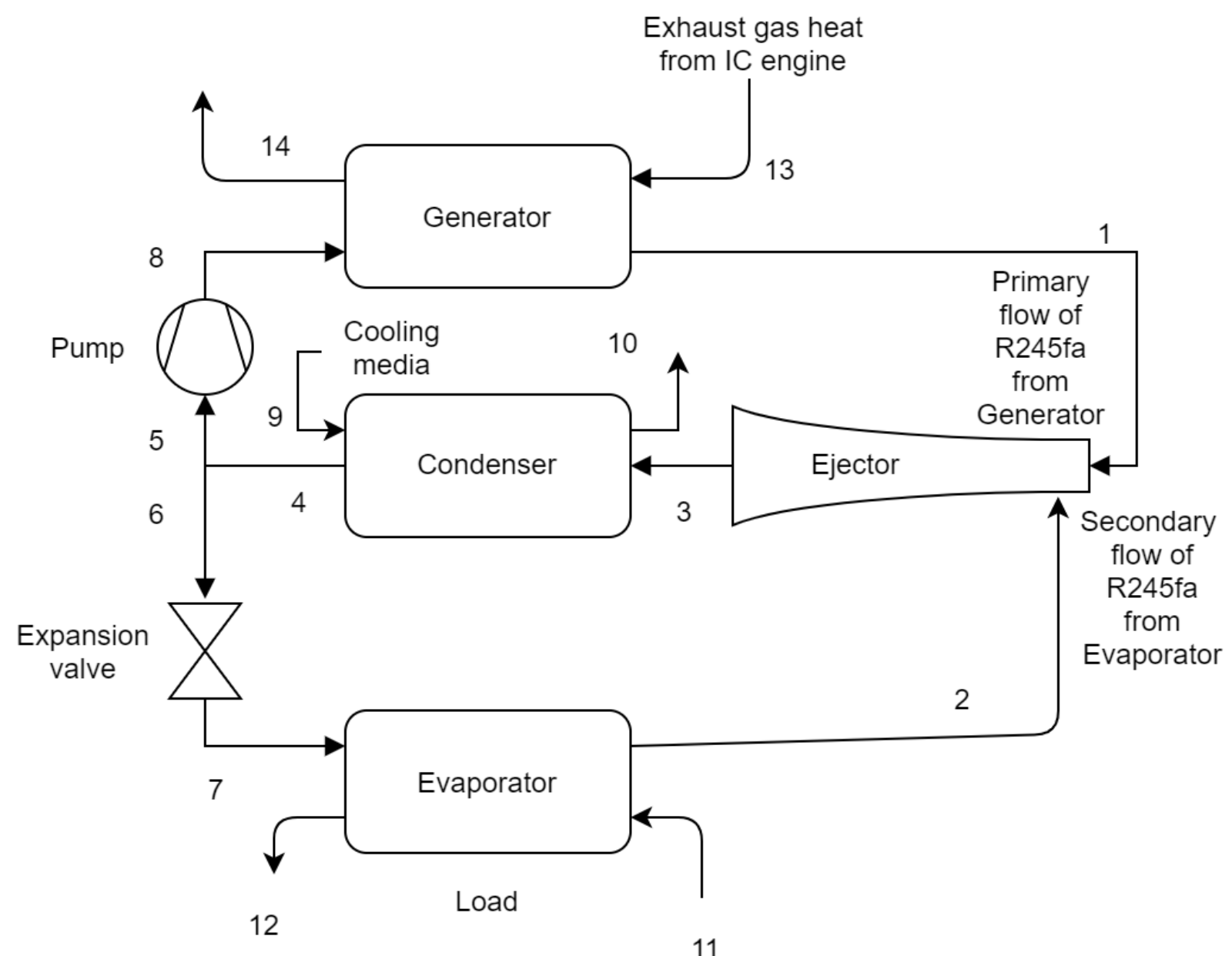

Fig. 1: Schematic diagram of ejector refrigeration system 


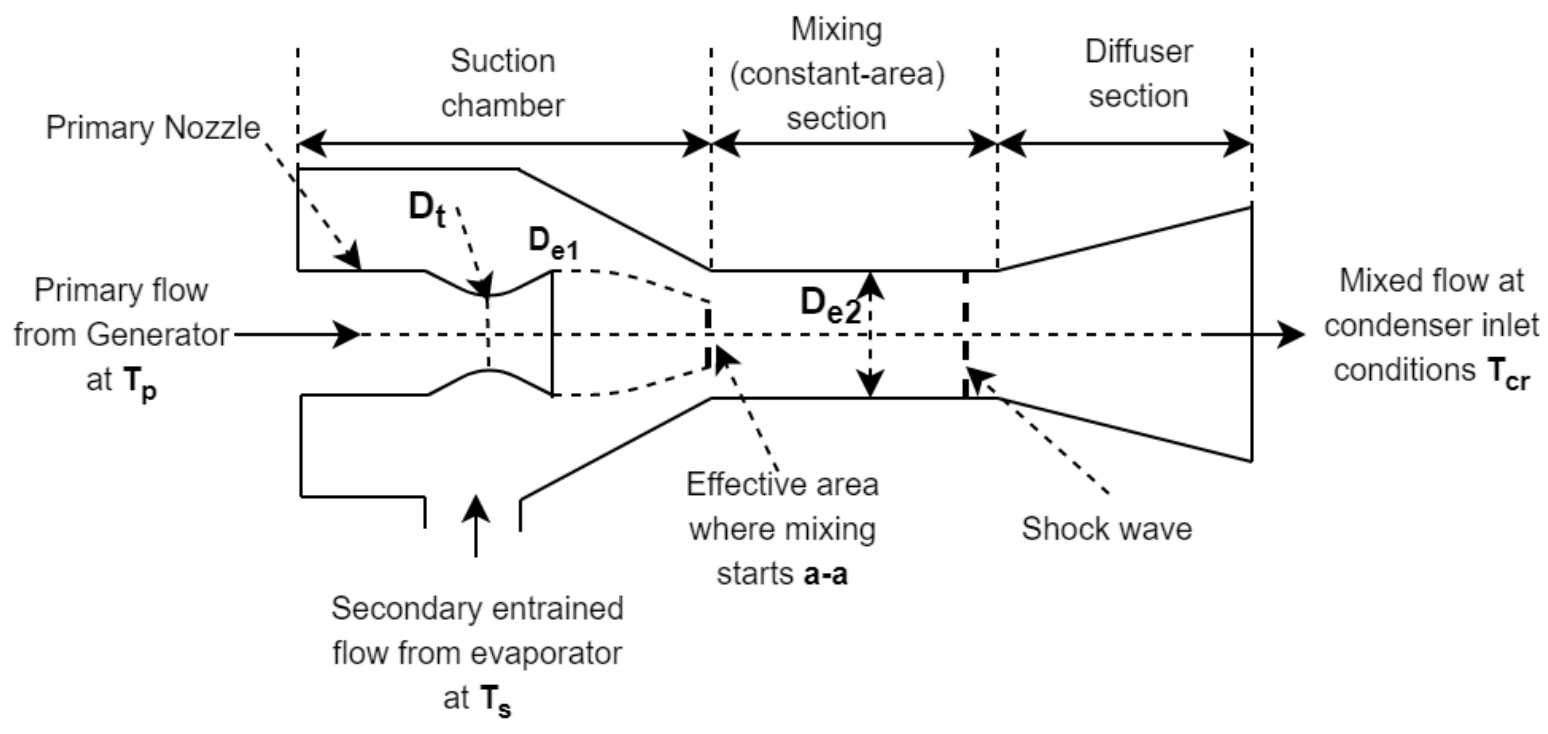

Fig. 2: Ejector component 


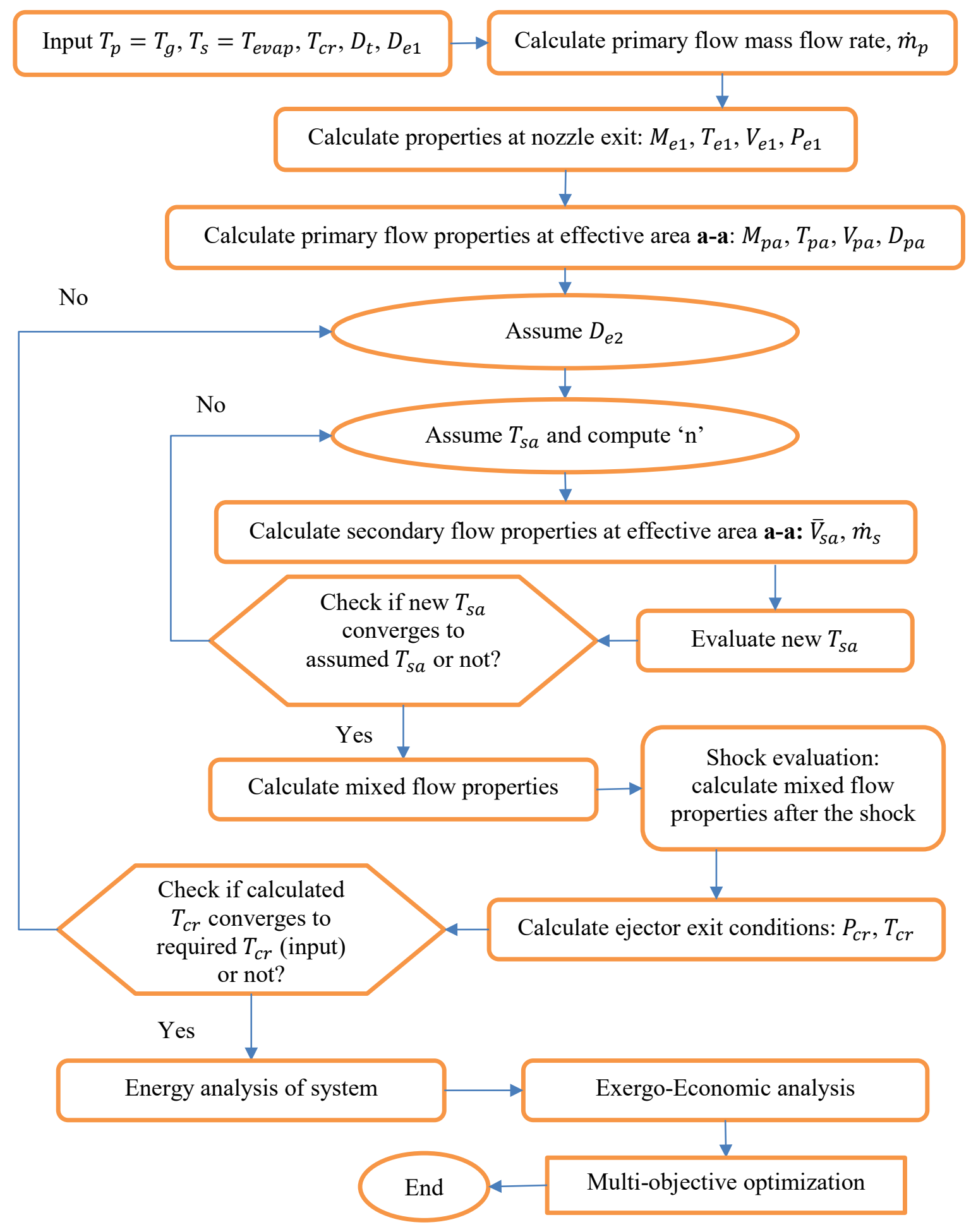

Fig. 3: Simulation Flowchart 


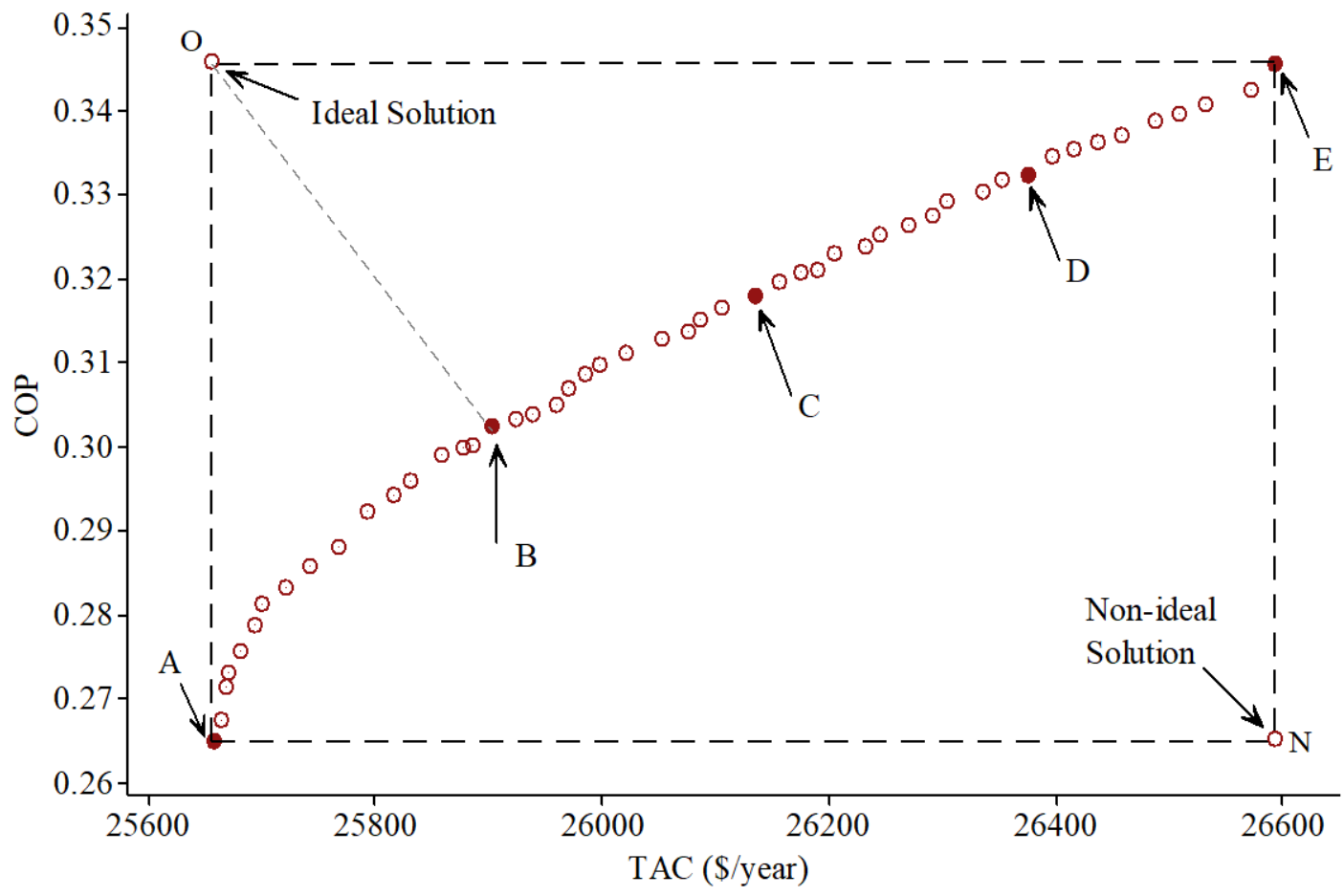

Fig. 4: Pareto frontier from multi-objective optimization 

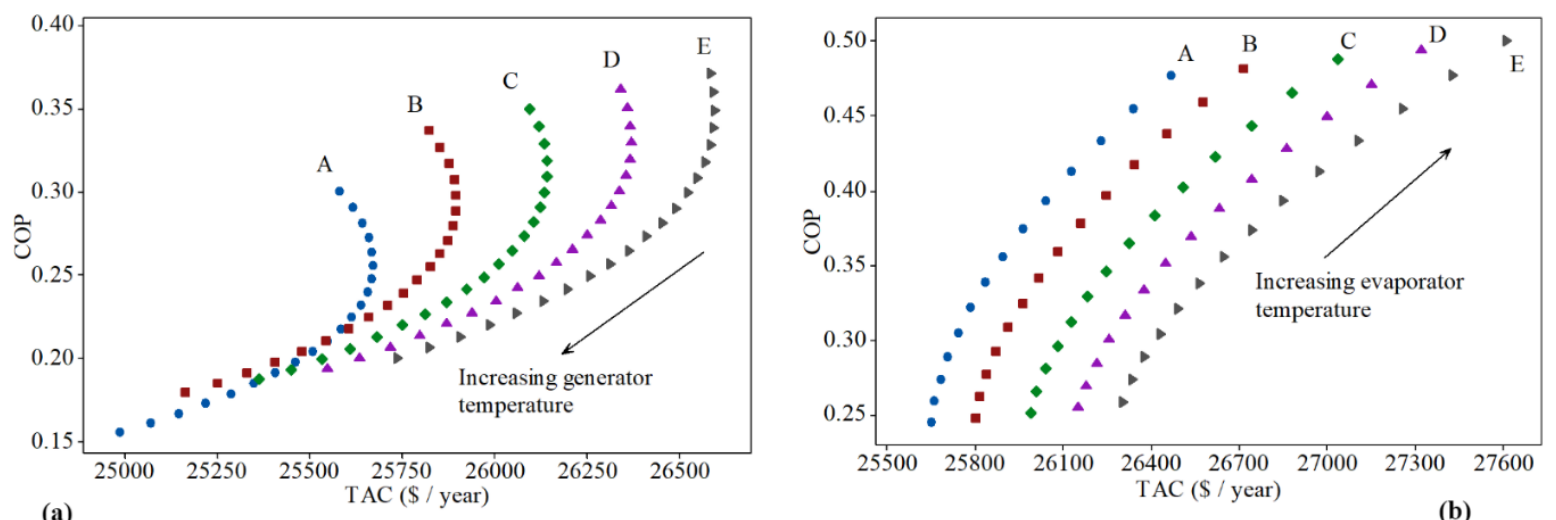

(a)

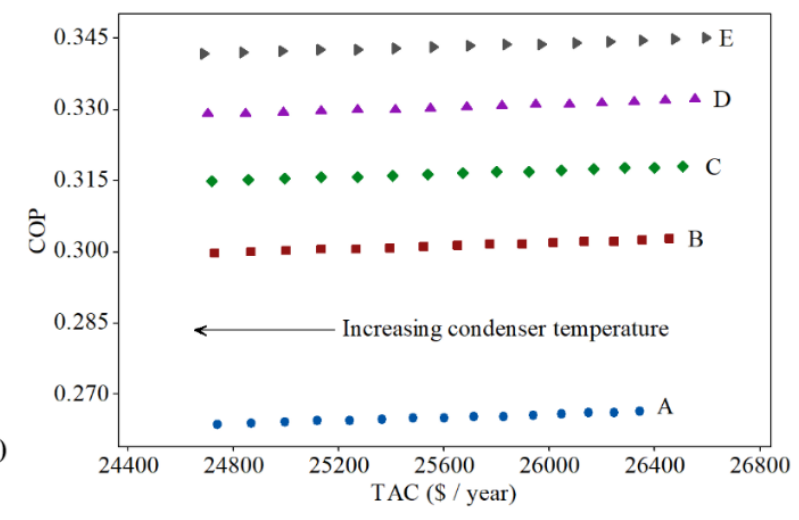

Fig. 5: Sensitivity of objective function to (a) generator temperature (b) evaporator temperature (c) condenser temperature 


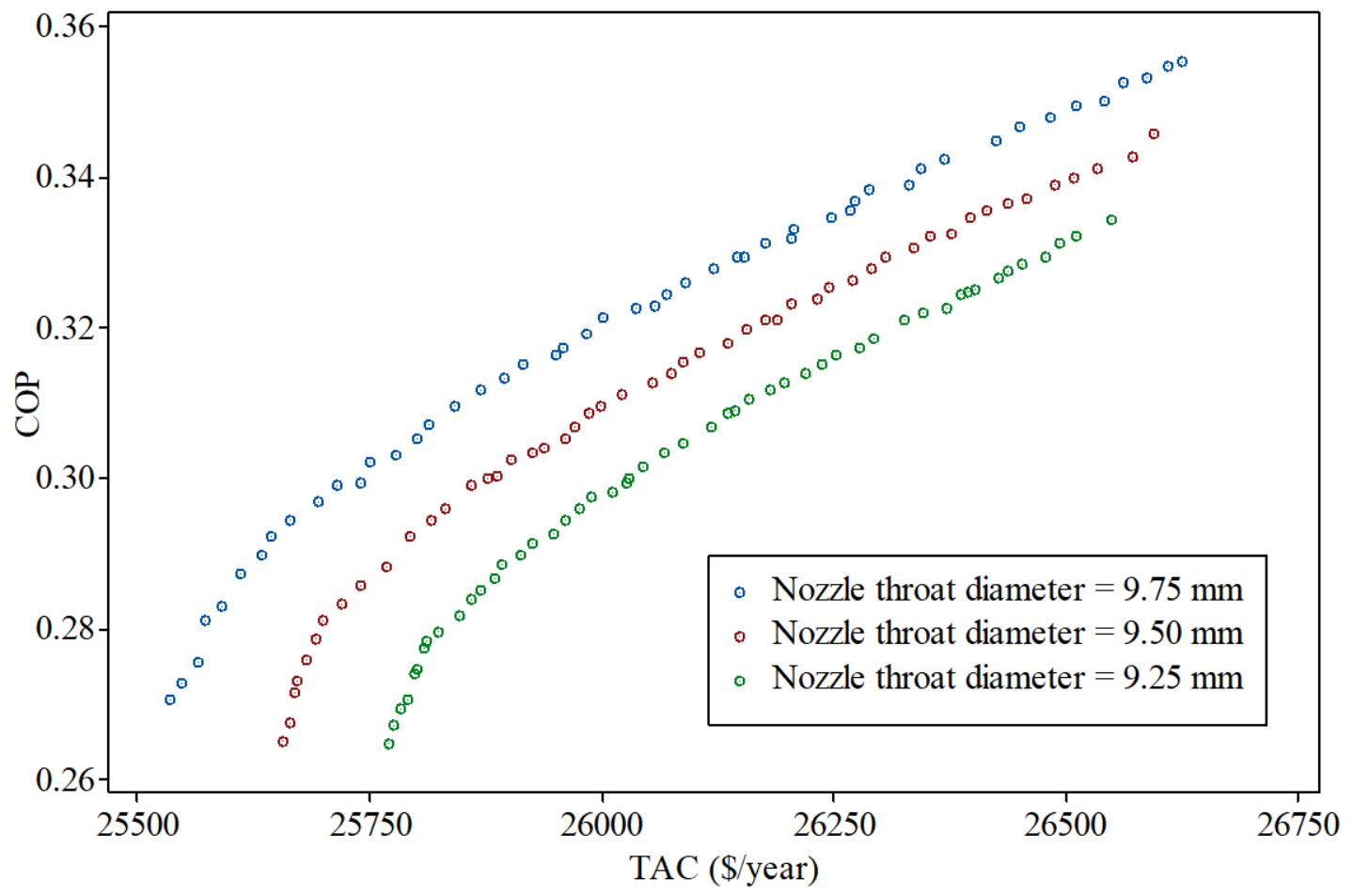

Fig. 6: Effect of nozzle throat diameter on Pareto solutions 


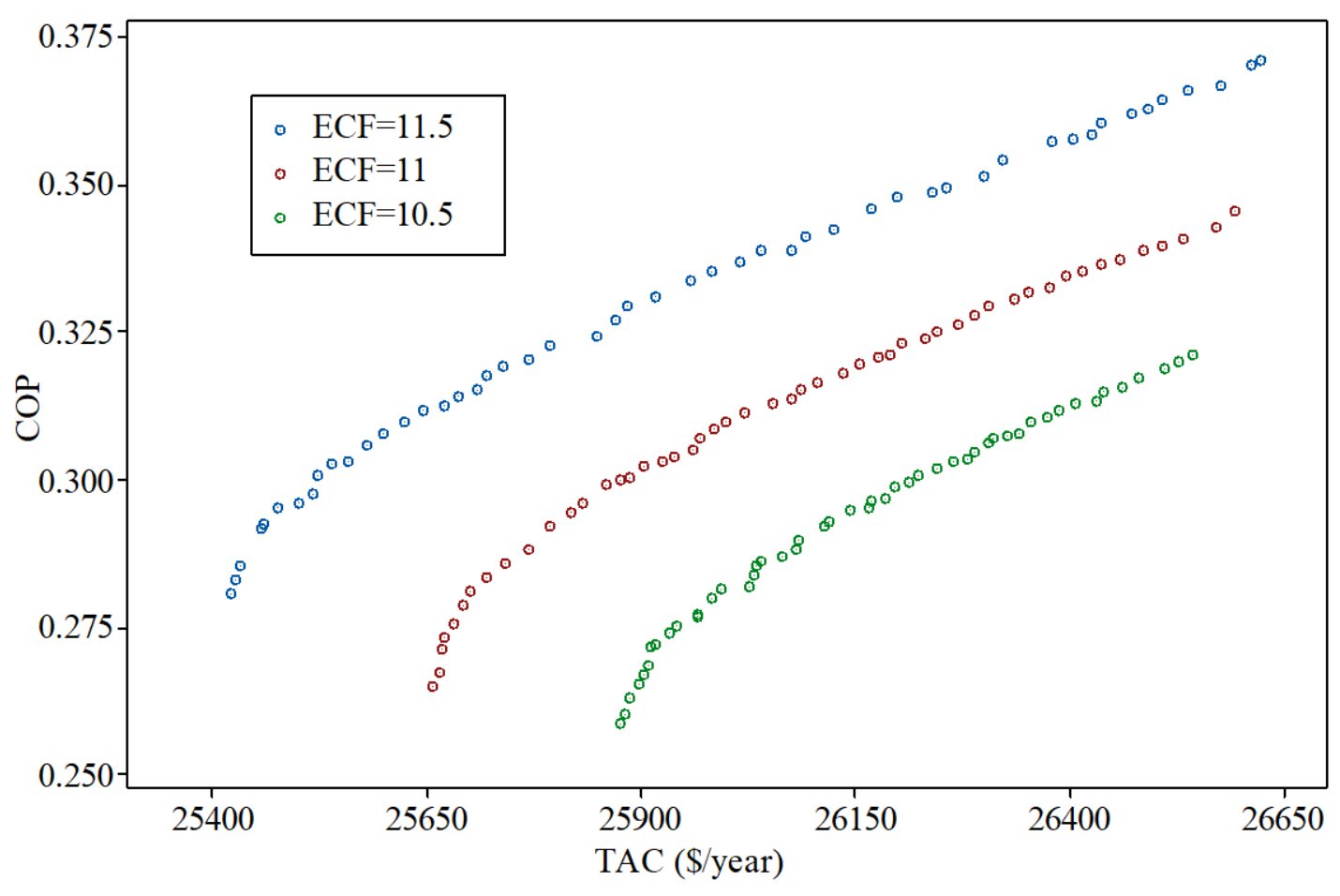

Fig. 7: Effect of Ecological function (ECF) on Pareto solutions 


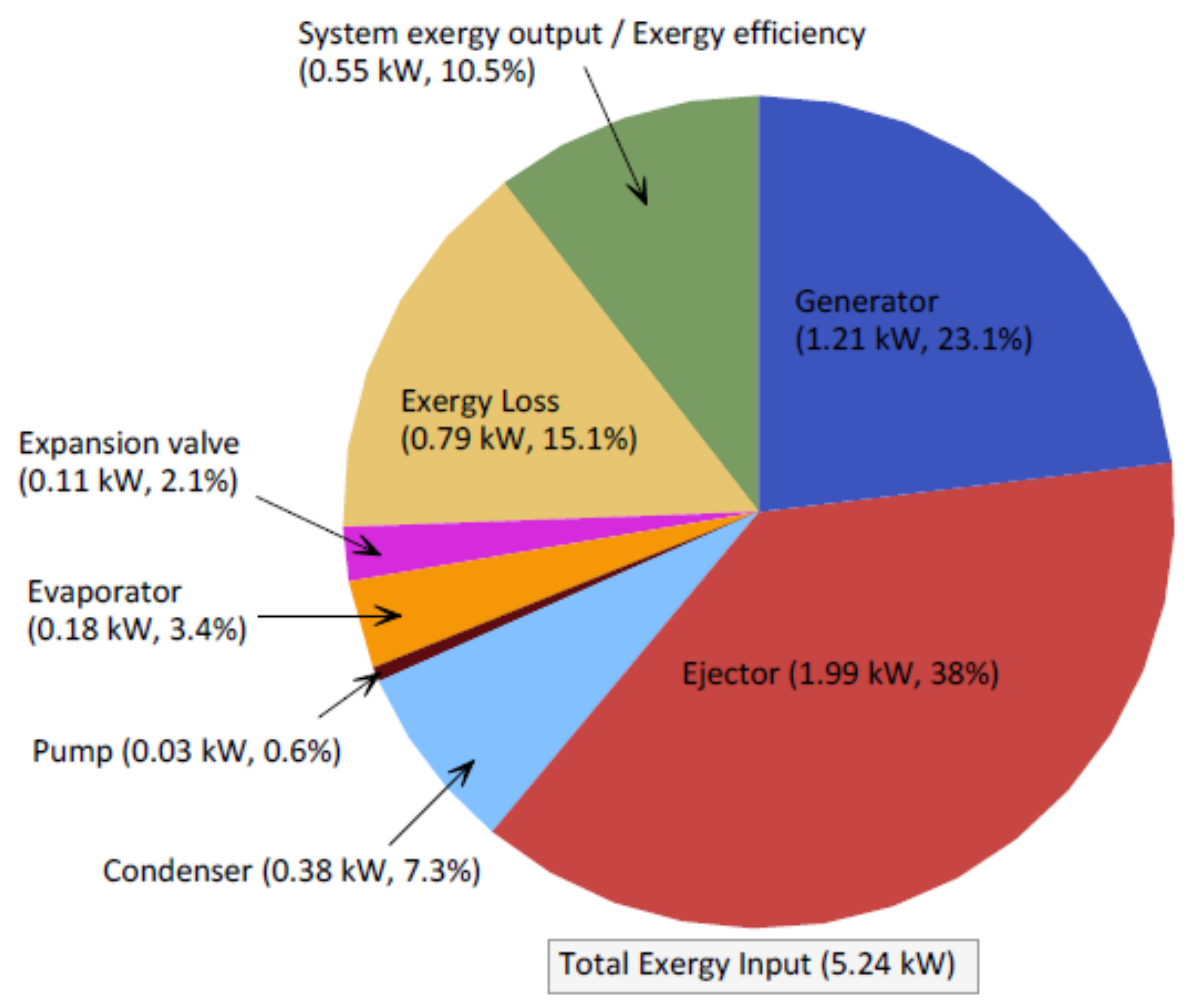

Fig. 8: Exergy destruction rate in system components at optimal point B 


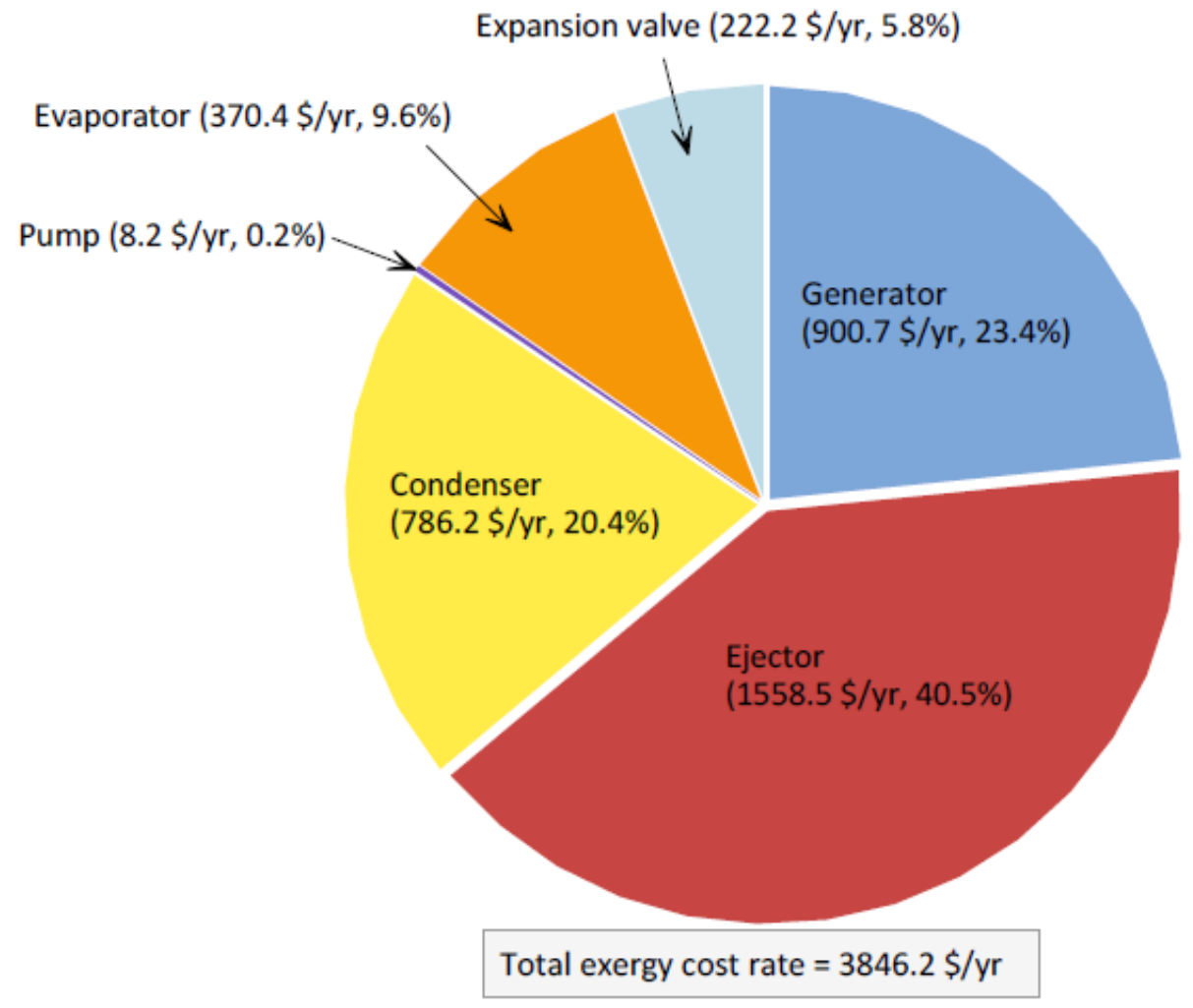

Fig. 9: Exergy cost rate in system components at optimal point B 
Table 1: Ejector component modelling (Zhu et al. 2007, Sadeghi et al. 2015)

\begin{tabular}{|c|c|}
\hline $\begin{array}{l}\text { Primary stream flow } \\
\text { rate at nozzle throat }\end{array}$ & $\dot{m}_{p}=P_{p} A_{t} \sqrt{\left(\frac{\gamma \eta_{p}}{R_{\text {gas }} T_{P}}\right)\left(\frac{2}{1+\gamma}\right)^{\left(\frac{\gamma+1}{\gamma-1}\right)}}$ \\
\hline \multirow{3}{*}{$\begin{array}{l}\text { Temperature, velocity } \\
\text { and Mach number at } \\
\text { the nozzle exit }\end{array}$} & $\frac{D_{e 1}}{D_{t}}=\sqrt{\left[\frac{2+(\gamma-1) M_{e 1}^{2}}{2+(\gamma-1)}\right]^{\left(\frac{\gamma+1}{2(\gamma-1)}\right)}\left(\frac{1}{M_{e 1}}\right)}$ \\
\hline & $\frac{T_{p}}{T_{e 1}}=1+\frac{1}{2}(\gamma-1) M_{e 1}^{2}$ \\
\hline & $V_{e 1}=M_{e 1} \sqrt{\gamma R_{g a s} T_{e 1}}$ \\
\hline \multirow{4}{*}{$\begin{array}{l}\text { primary flow Mach } \\
\text { number, temperature, } \\
\text { velocity and effective } \\
\text { diameter at effective } \\
\text { area (a-a) }\end{array}$} & $\frac{P_{p}}{P_{s}}=\left[1+\frac{1}{2}(\gamma-1) M_{p a}^{2}\right]^{\left(\frac{\gamma}{\gamma-1}\right)}$ \\
\hline & $\frac{T_{p}}{T_{p a}}=1+\frac{1}{2}(\gamma-1) M_{p a}^{2}$ \\
\hline & $V_{p a}=M_{p a} \sqrt{\gamma R_{g a s} T_{p a}}$ \\
\hline & $\left(\frac{D_{p a} \sqrt{\eta_{p} \eta_{s}}}{D_{e 1}}\right)^{2}=\left[\frac{2+(\gamma-1) M_{p a}^{2}}{2+(\gamma-1) M_{e 1}^{2}}\right]^{\left(\frac{\gamma+1}{2(\gamma-1)}\right)}\left(\frac{M_{e 1}}{M_{p a}}\right)$ \\
\hline \multirow{3}{*}{$\begin{array}{l}\text { Velocity and mass } \\
\text { flow rate of } \\
\text { secondary entrained } \\
\text { stream at a-a }\end{array}$} & $\bar{V}_{s a}=\frac{2 V_{p a}}{\left(R_{e 2}^{2}-R_{p a}^{2}\right)}\left[\frac{n R_{e 2}^{2}}{n+1}\left(1-\frac{R_{p a}}{R_{e 2}}\right)^{\left(\frac{n+1}{n}\right)}-\frac{n R_{e 2}^{2}}{2 n+1}\left(1-\frac{R_{p a}}{R_{e 2}}\right)^{\left(\frac{2 n+1}{n}\right)}\right]$ \\
\hline & $\dot{m}_{s}=\frac{2 \pi P_{s} V_{p a}}{R_{g a s} T_{s a}}\left[\frac{n R_{e 2}^{2}}{n+1}\left(1-\frac{R_{p a}}{R_{e 2}}\right)^{\left(\frac{n+1}{n}\right)}-\frac{n R_{e 2}^{2}}{2 n+1}\left(1-\frac{R_{p a}}{R_{e 2}}\right)^{\left(\frac{2 n+1}{n}\right)}\right]$ \\
\hline & $n=\frac{\ln \left(1-\frac{D_{p a}}{D_{e 2}}\right)}{\ln \left(\frac{\sqrt{T_{s a / T_{p a}}}}{M_{p a}}\right)}$ \\
\hline \multirow{3}{*}{$\begin{array}{l}\text { Velocity, } \\
\text { temperature and } \\
\text { specific volume of } \\
\text { mixed flow before } \\
\text { shock }\end{array}$} & $V_{m}=\frac{\dot{m}_{p} V_{p a}+\dot{m}_{s} V_{s} a}{\dot{m}_{p}+\dot{m}_{s}}$ \\
\hline & $T_{m}=\frac{\dot{m}_{p}\left(C_{p} T_{p a}+\frac{V_{p a}^{2}}{2}\right)+\dot{m}_{s}\left(C_{p} T_{s a}+\frac{V_{s a}^{2}}{2}\right)-\left(\dot{m}_{p}+\dot{m}_{s}\right)\left(\frac{V_{m}^{2}}{2}\right)}{\left(\dot{m}_{p}+\dot{m}_{s}\right) C_{p}}$ \\
\hline & $v_{m}=\frac{V_{m} A_{e 2}}{\dot{m}_{p}+\dot{m}_{s}}$ \\
\hline \multirow{2}{*}{$\begin{array}{l}\text { Pressure and Mach } \\
\text { number of mixed } \\
\text { flow After shock }\end{array}$} & $\frac{P_{e 2}}{P_{m}}=1+\frac{2 \gamma}{(\gamma+1)}\left(M_{m}^{2}-1\right)$ \\
\hline & $M_{e 2}=\sqrt{\frac{1+\left(\frac{\gamma-1}{2}\right) M_{m}^{2}}{\gamma M_{m}^{2}-\left(\frac{\gamma-1}{2}\right)}}$ \\
\hline Diffuser efficiency & $\eta_{d}=\frac{T_{e 2}-T_{d}}{T_{e 2}-T_{c r}}$ \\
\hline
\end{tabular}


Table 2: Energy analysis based governing equations

Heat transfer rate in generator: $\quad \dot{Q}_{g}=\dot{m}_{p}\left(h_{1}-h_{8}\right)$

Heat transfer rate in evaporator: $\quad \dot{Q}_{\text {evap }}=\dot{m}_{s}\left(h_{2}-h_{7}\right)$

Heat transfer rate in condenser: $\quad \dot{Q}_{c r}=\left(\dot{m}_{s}+\dot{m}_{p}\right)\left(h_{3}-h_{4}\right)$

Pump work:

$$
\dot{W}_{\text {pump }}=\frac{\dot{m}_{p} g H_{\text {pump }}}{\eta_{\text {pump }}}=\frac{\dot{m}_{p}}{\eta_{\text {pump }}}\left(\frac{P_{g}-P_{c r}}{\rho}\right)
$$

COP:

$$
\frac{\dot{Q}_{\text {evap }}}{\dot{Q}_{g}+\dot{W}_{\text {pump }}}
$$


Table 3: Exergy destruction in components

\begin{tabular}{ll}
\hline Component & Exergy destruction rate \\
\hline Generator & $\dot{E}_{D}=\left(\dot{E}_{8}-\dot{E}_{1}\right)+\left(\dot{E}_{13}-\dot{E}_{14}\right)$ \\
Ejector & $\dot{E}_{D}=\left(\dot{E}_{1}+\dot{E}_{2}\right)-\dot{E}_{3}$ \\
Evaporator & $\dot{E}_{D}=\left(\dot{E}_{7}-\dot{E}_{2}\right)+\left(\dot{E}_{11}-\dot{E}_{12}\right)$ \\
Condenser & $\dot{E}_{D}=\left(\dot{E}_{3}-\dot{E}_{4}\right)+\left(\dot{E}_{9}-\dot{E}_{10}\right)$ \\
Pump & $\dot{E}_{D}=\left(\dot{E}_{5}-\dot{E}_{8}\right)+\dot{W}_{p u m p}$ \\
\hline
\end{tabular}


Table 4: cost balance in components

\begin{tabular}{ll}
\hline Component & Equation of cost balance \\
\hline Generator & $\dot{C}_{13}+\dot{C}_{8}+\dot{Z}_{g}=\dot{C}_{14}+\dot{C}_{1}$ \\
Ejector & $\dot{C}_{1}+\dot{C}_{2}=\dot{C}_{3}$ \\
Evaporator & $\dot{C}_{11}+\dot{C}_{7}+\dot{Z}_{\text {evap }}=\dot{C}_{12}+\dot{C}_{2}$ \\
Condenser & $\dot{C}_{9}+\dot{C}_{3}+\dot{Z}_{c r}=\dot{C}_{10}+\dot{C}_{4}$ \\
Pump & $\dot{C}_{5}+\dot{Z}_{\text {pump }, \text { motor }}=\dot{C}_{8}-\dot{C}_{W, p}$ \\
Separation point & $\dot{C}_{4}=\dot{C}_{5}+\dot{C}_{6}$ \\
\hline
\end{tabular}


Table 5: Auxiliary equations for components

\begin{tabular}{ll}
\hline Component & Auxiliary equation \\
\hline Generator & $\frac{\dot{C}_{13}}{\dot{E}_{13}}=\frac{\dot{C}_{14}}{\dot{E}_{14}} \quad$ or $\quad u_{13}=u_{14}$ \\
Evaporator & $\frac{\dot{C}_{2}}{\dot{E}_{2}}=\frac{\dot{C}_{7}}{\dot{E}_{7}} \quad$ or $\quad u_{2}=u_{7}$ \\
Condenser & $\frac{\dot{C}_{3}}{\dot{E}_{3}}=\frac{\dot{C}_{4}}{\dot{E}_{4}} \quad$ or $\quad u_{3}=u_{4}$ \\
Expansion valve & $\frac{\dot{C}_{6}}{\dot{E}_{6}}=\frac{\dot{C}_{7}}{\dot{E}_{7}} \quad$ or $\quad u_{6}=u_{7}$ \\
Separation point & $\frac{\dot{C}_{6}}{\dot{C}_{5}}=\frac{\dot{m}_{s}}{\dot{m}_{p}}$
\end{tabular}


Table 6: Design variable ranges and constraints

\begin{tabular}{lcccl}
\hline & \multicolumn{2}{c}{ Range } & Reason \\
\cline { 2 - 4 } Design variables & $\begin{array}{c}\text { Lower } \\
\text { limit }\end{array}$ & $\begin{array}{c}\text { Upper } \\
\text { limit }\end{array}$ \\
\hline Evaporator temperature, $T_{\text {evap }}(\mathrm{K})$ & 271 & 285 & Availability in the market \\
Generator temperature, $T_{g}(\mathrm{~K})$ & 348 & 368 & $\begin{array}{l}\text { Temperature range available from } \\
\text { heat source }\end{array}$ \\
Condenser temperature, $T_{c r}(\mathrm{~K})$ & 306 & 313 & $\begin{array}{l}\text { Practical range for water based } \\
\text { cooling in condenser }\end{array}$ \\
\hline
\end{tabular}

Constraints used

\begin{tabular}{ll}
\hline$T_{14}>T_{g}$ & $\begin{array}{l}\text { To ensure the positive temperature gradient } \\
\text { throughout the generator }\end{array}$ \\
$\dot{Q}_{g}<33 \mathrm{~kW}$ & The constant heat input from source is $33 \mathrm{~kW}$ \\
$\mathrm{ECF}=11$ & To fix the ecological function to a value
\end{tabular}


Table 7: Optimal parameters at selected design points (A-E)

\begin{tabular}{llllll}
\hline & $\mathrm{A}$ & $\mathrm{B}$ & $\mathrm{C}$ & $\mathrm{D}$ & $\mathrm{E}$ \\
\hline Evaporator temperature, $\boldsymbol{T}_{\boldsymbol{e v a \boldsymbol { p }}}(\mathrm{K})$ & 272.4 & 274.6 & 275.3 & 275.9 & 276.4 \\
Generator temperature, $\boldsymbol{T}_{\boldsymbol{g}}(\mathrm{K})$ & 351.9 & 351.6 & 351.2 & 350.8 & 350.4 \\
Condenser temperature, $\boldsymbol{T}_{\boldsymbol{c r}}(\mathrm{K})$ & 309.2 & 308.5 & 307.6 & 306.8 & 306.0 \\
Coefficient of performance, $\boldsymbol{C O P}$ & 0.26 & 0.30 & 0.32 & 0.33 & 0.35 \\
Total annual cost, $\boldsymbol{T} \boldsymbol{A} \boldsymbol{C}(\mathbf{\$} / \mathrm{y})$ & 25657 & 25903 & 26134 & 26376 & 26594 \\
\hline
\end{tabular}


Table 8: State properties and costs at optimal point B

\begin{tabular}{|c|c|c|c|c|c|c|}
\hline \multirow[t]{2}{*}{ State } & \multirow[t]{2}{*}{ Fluid } & \multirow{2}{*}{$\begin{array}{c}\mathrm{T} \\
(\mathrm{K})\end{array}$} & \multirow{2}{*}{$\begin{array}{c}\text { Mass } \\
\text { flow rate } \\
(\mathrm{kg} / \mathrm{s})\end{array}$} & \multirow{2}{*}{$\begin{array}{c}\text { Exergy } \\
\text { rate } \\
(\mathrm{kW})\end{array}$} & \multicolumn{2}{|c|}{ Costs } \\
\hline & & & & & $\begin{array}{c}\dot{C} \\
(\$ / y)\end{array}$ & $\begin{array}{c}u \\
(\$ / G J)\end{array}$ \\
\hline 1 & R245fa & 351.6 & 0.113 & 4.022 & 4210.1 & 33.2 \\
\hline 2 & $\mathrm{R} 245 \mathrm{fa}$ & 274.6 & 0.043 & -0.823 & -1708.3 & 65.8 \\
\hline 3 & R245fa & 308.5 & 0.156 & 1.206 & 2501.8 & 65.8 \\
\hline 4 & $\mathrm{R} 245 \mathrm{fa}$ & 308.5 & 0.156 & 0.034 & 71.4 & 65.8 \\
\hline 5 & $\mathrm{R} 245 \mathrm{fa}$ & 308.5 & 0.113 & 0.025 & 51.6 & 65.8 \\
\hline 6 & $\mathrm{R} 245 \mathrm{fa}$ & 308.5 & 0.043 & 0.010 & 19.7 & 65.8 \\
\hline 7 & $\mathrm{R} 245 \mathrm{fa}$ & 274.6 & 0.043 & -0.098 & -202.5 & 65.8 \\
\hline 8 & R245fa & 308.7 & 0.113 & 0.052 & 164.3 & 99.8 \\
\hline 9 & Water & 303.5 & 2.741 & 0.336 & 0 & 0 \\
\hline 10 & Water & 306.5 & 2.741 & 1.128 & 2712.7 & 76.2 \\
\hline 11 & Water & 282.6 & 0.408 & 0.704 & 0 & 0 \\
\hline 12 & Water & 277.6 & 0.408 & 1.251 & 2123.3 & 53.8 \\
\hline
\end{tabular}


Table 9: Thermal model validations

\section{(a) Ejector system model validation}

\begin{tabular}{lccc}
\hline Ejector system model validation with the results of Sadeghi et al. (2015). \\
\begin{tabular}{l}
$T_{g}=367.54 \mathrm{~K}, T_{c r}=306.44 \mathrm{~K}, T_{\text {evap }}=273.03 \mathrm{~K}, D_{t}=9.35 \mathrm{~mm}, D_{e 1}=14.93 \mathrm{~mm}$ \\
\hline Parameters
\end{tabular} & \multicolumn{2}{c}{ Values with R141b as refrigerant } \\
\cline { 2 - 4 } & 0.14 & 0.1441 & -2.93 \\
\hline Coefficient of performance & 3.09 & 3.055 & 1.13 \\
Second law efficiency $(\%)$ & 0.1573 & 0.1569 & 0.25 \\
Primary flow rate, $\dot{m}_{p}(\mathrm{~kg} / \mathrm{s})$ & 0.0302 & 0.0299 & 0.99 \\
Secondary flow rate, $\dot{m}_{s}(\mathrm{~kg} / \mathrm{s})$ & 28.27 & 28.29 & -0.06 \\
Constant area diameter, $D_{e 2}(\mathrm{~mm})$ & 6.03 & 5.9566 & 1.22 \\
Refrigeration effect, $\dot{Q}_{\text {evap }}(\mathrm{kW})$ & & & Eresent model \\
\hline
\end{tabular}


(b) Ejector component model validation

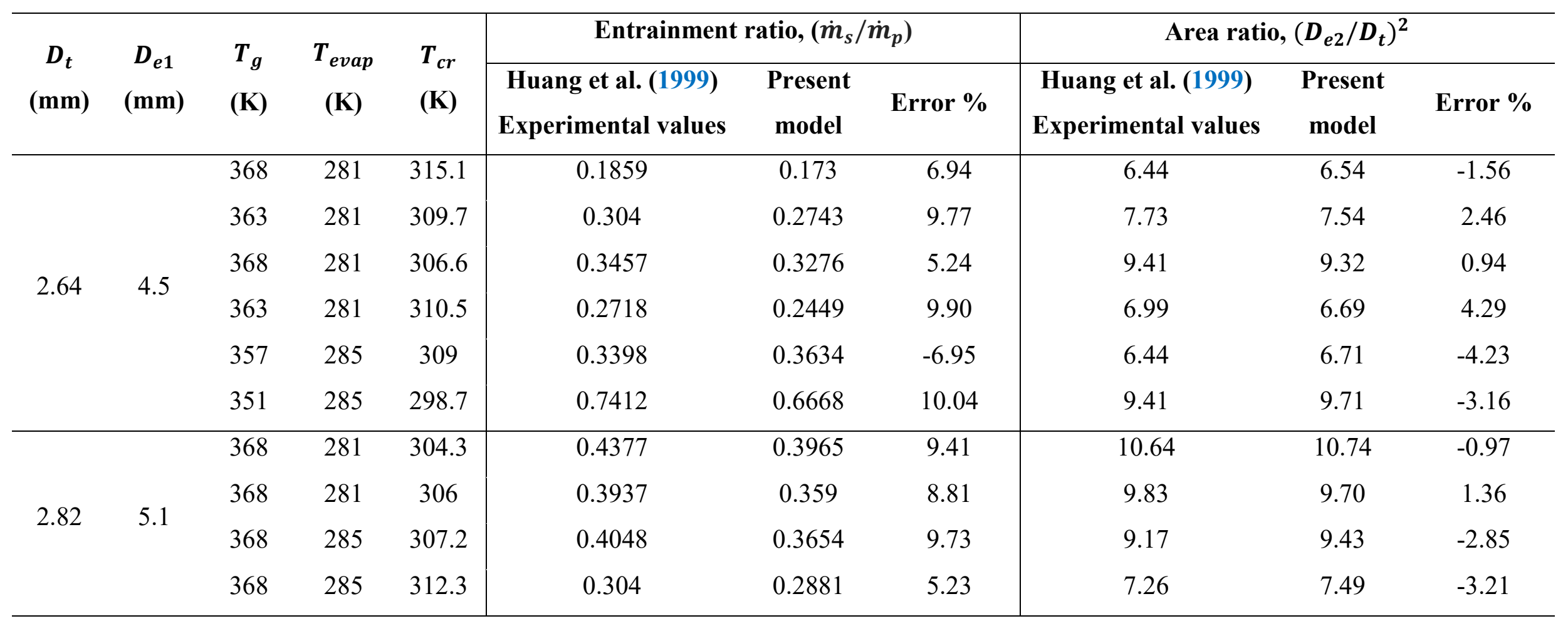


Table 10: Effect of pump isentropic efficiency

\begin{tabular}{cccc}
\hline At optimal point B & \multicolumn{3}{c}{ Isentropic efficiency } \\
\cline { 2 - 4 }$(\mathrm{COP}=0.3, \mathrm{TAC}=25903$ \$/year $)$ & 0.6 & 0.5 & 0.4 \\
\hline \% rise in Pump work & 67 & 100 & 150 \\
\% drop in COP & 0.8 & 1.4 & 2 \\
\% rise in TAC & 0.3 & 0.6 & 1.1 \\
\hline
\end{tabular}

